\title{
Angka Keamanan Piping di Bawah Tubuh Bendungan dengan Metode Harza
}

\author{
Husna Alghoida ${ }^{1}$; Dyah Pratiwi Kusumastuti ${ }^{2}$ \\ ${ }^{1,2}$ Program Studi Teknik Sipil, Fakultas Teknologi Infrastruktur dan Kewilayahan, \\ Institut Teknologi PLN \\ ${ }^{2}$ dyah.pratiwi@itpln.ac.id
}

\begin{abstract}
Dams have many benefits such as irrigation, flood prevention, power generation and even tourism, especially in areas where the dam is located. So that the benefits received can last a long time, in the planning, it must be analyzed for stability, seepage discharge that occurs and the safety of the piping. The piping hazard safety figures in this study were calculated using the Harza method for maximum water level conditions, normal water levels, fast receding and empty dams at sta $0+$ 150 , sta $0+200$, sta $0+250$ and sta $0+300$. Based on the calculation results, it is found that the safety of piping hazards without filters with the grouting method do not meet the requirements safety factor, especially in conditions of maximum water level, normal water level and fast receding. In order for the safety of piping hazard in order to meet the requirements, a filter is applied under the dams. The filter is applied so that the piping hazard safety figure meets the requirements of all water level conditions and all station is $80 \mathrm{~cm}$ deep.
\end{abstract}

Keywords: safety factor, piping, Harza method, filter

\begin{abstract}
ABSTRAK
Bendungan memiliki banyak manfaat seperti irigasi, pencegah banjir, pembangkit listrik bahkan pariwisata khususnya pada wilayah dimana bendungan tersebut berada. Agar manfaat yang diterima dapat berlangsung lama maka dalam perencanaannya wajib dianalisis terhadap stabilitas, debit rembesan yang terjadi maupun keamanan dari piping. Angka keamanan bahaya piping pada penelitian ini dihitung dengan menggunakan metode Harza untuk kondisi muka air maksimum, muka air normal, surut cepat dan bendungan kosong di sta 0+150, sta 0+200, sta $0+250$ serta sta 0+300. Berdasarkan hasil perhitungan didapatkan bahwa angka keamanan bahaya piping tanpa penggunaan filter dengan metode grouting tidak memenuhi persyaratan angka keamanan khususnya pada kondisi muka air maksimum, muka air normal dan surut cepat. Agar angka keamanan bahaya piping memenuhi persyaratan maka diaplikasikan filter dibawah tubuh bendungan. Filter yang diaplikasikan agar angka keamanan bahaya piping memenuhi persyaratan diseluruh kondisi muka air dan seluruh sta adalah dengan kedalaman $80 \mathrm{~cm}$.
\end{abstract}

Kata kunci: angka keamanan, piping, metode Harza, filter 


\section{JURNAL FORUM MEKANIKA}

Vol. 10, No. 1, Mei 2021, P-ISSN: 2356-1491, E-ISSN: 2655-8211

DOI: https://doi.org/10.33322/forummekanika.v10i7.1266

\section{PENDAHULUAN}

Pembangunan infrastruktur khususnya bendungan pada suatu daerah akan memberikan peranan penting untuk kemajuan di daerah tersebut karena manfaat yang didapatkan oleh masyarakat sekitarnya [1]. Manfaat yang didapatkan untuk kehidupan manusia antara lain pembangkit listrik, mencegah banjir, menstabilkan aliran air [2], penyediaan air baku dan pariwisata [3]. Dalam perencanaan bendungan agar aman dan sesuai usia pelayanan sesuai yang direncanakan diperlukan analisis stabilitas tubuh bendungan dari berbagai aspek [4].

Khususnya bendungan tipe urugan yang sangat rentan akan keruntuhan yang disebabkan oleh tekanan hidrostatik, tekanan air pori, beban gempa dan dari bentuk geometrik bendungannya sendiri [5]. [6] Juga menyatakan overtoping, pintu air tidak berfungsi, stabilitas lereng, internal erotion dan piping merupakan beberapa penyebab kegagalan bendungan urugan, baik urugan tanah maupun urugan batuan. Untuk mencegah kemungkinan terjadinya keruntuhan atau kegagalan serta bendungan dapat memberikan manfaat dalam waktu yang panjang [7], maka diperlukan analisis terhadap stabilitas urugan atau timbunan tubuh bendungan dan besarnya debit rembesan di bawah tubuh bendungan khususnya angka keamanan pada bahaya piping.

Pada penelitian ini akan dianalisis angka keamanan bahaya piping dengan variasi muka air dan beberapa titik sta. Perhitungan dengan variasi muka air karena perubahan ketinggian air di bendungan mempengaruhi besarnya debit rembesan [7] sehingga analisis angka keamanan ditinjau pada muka air maksimum (HWL), muka air normal (NWL), kondisi surut cepat dan bendungan kosong.

\section{METODE/PERANCANGAN PENELITIAN}

\subsection{Lokasi Penelitian dan Pengumpulan Data}

Analisis angka keamanan dari piping yang dilakukan pada penelitian ini mengambil obyek Bendungan Leuwikeris, Ciamis-Tasikmalaya khususnya pada struktur tubuh bendungan utama. Secara geografis, wilayah Bendungan Leuwikeris berada pada posisi : $108^{\circ} 23^{\prime} 43,00^{\prime \prime}$ BT dan $0.7^{\circ} 21^{\prime} 42,00^{\prime \prime}$ LS dan secara administrasi berada pada dua wilayah Kabupaten, yaitu Kabupaten Tasikmalaya dan Kabupaten Ciamis.

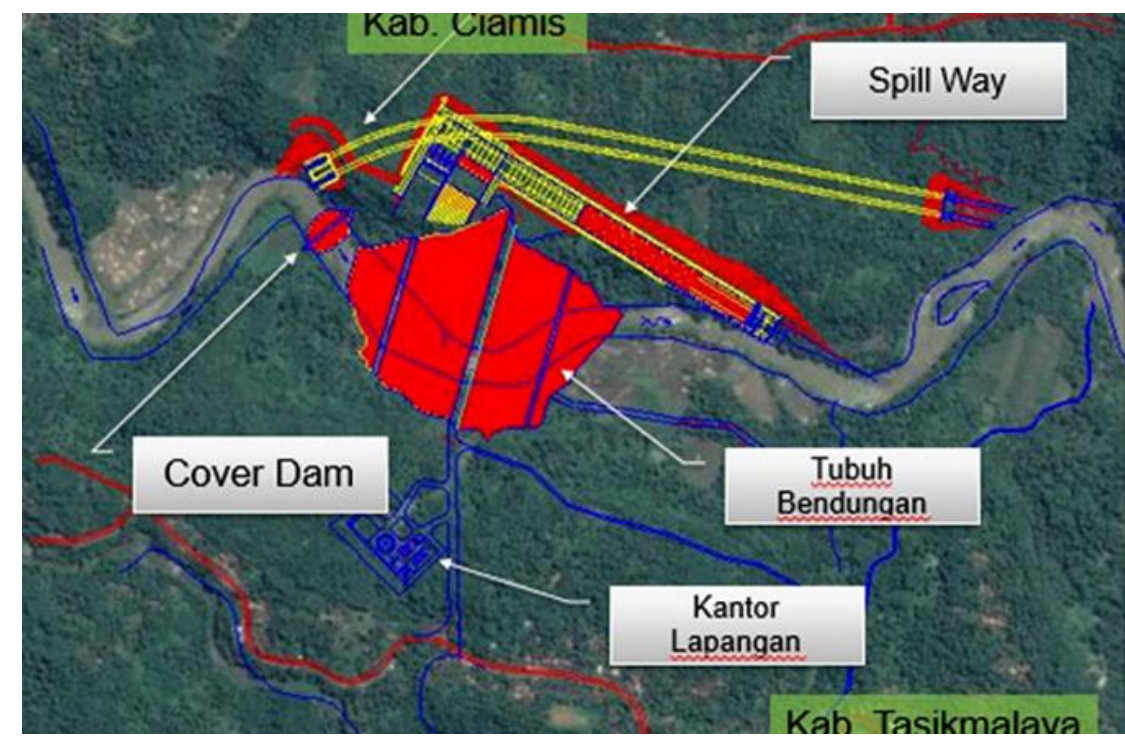

Gambar 1. Lokasi Tubuh Bendungan

Sumber: www.initasik.com 
Data yang digunakan pada penelitian ini merupakan data sekunder yaitu data yang didapat dari dokumen-dokumen dari instansi terkait dengan perencanaan bendungan [3]. Data-data yang digunakan dalam analisis yaitu peta topografi, data tinggi muka air maksimum, data parameter tanah dan gambar kerja desain bendungan. Data tanah yang digunakan dalam analisis yaitu berat jenis tanah, angka pori tanah dan koefisien permeabilitas pondasi bendungan. Data-data tanah yang digunakan sebagai berikut:

Tabel 1. Parameter Tanah

\begin{tabular}{|c|c|c|}
\hline No. & Paraneter & Keterangan \\
\hline 1 & Berat jenis (Gs) & 2,62 \\
\hline 2 & Angka pori (e) & 0,30 \\
\hline
\end{tabular}

Tabel 2. Parameter Koefisien Permeabilitas

\begin{tabular}{|c|c|c|c|}
\hline \multirow{2}{*}{ Material } & \multicolumn{3}{|c|}{ Permeabilitas } \\
\cline { 2 - 4 } & $\mathbf{K}(\mathbf{c m} / \mathbf{d e t})$ & $\boldsymbol{K}_{\boldsymbol{h}}(\mathbf{m} / \mathbf{d e t})$ & $\boldsymbol{K}_{\boldsymbol{v}}(\mathbf{m} / \mathbf{d e t})$ \\
\hline Inti Lempung & $1,010^{-6}$ & $5,010^{-8}$ & $1,010^{-8}$ \\
\hline Filter & $1,010^{-3}$ & $1,010^{-5}$ & $1,010^{-5}$ \\
\hline Transisi & $5,010^{-3}$ & $5.010^{-5}$ & $5.010^{-5}$ \\
\hline Urugan Batu & $1,010^{-2}$ & $1,010^{-4}$ & $1,010^{-4}$ \\
\hline Breksi Vulkanik Lapuk Sedang & $3,9910^{-4}$ & $3,9910^{-6}$ & $3,9910^{-6}$ \\
\hline Breksi Vulkanik Lapuk Ringan & $1,0010^{-5}$ & $1,0010^{-7}$ & $1,0010^{-7}$ \\
\hline
\end{tabular}

\subsection{Tahapan Analisis}

Permasalahan yang umumnya terjadi ditubuh bendungan maupun dibawah tubuh bendungan adalah rembesan, karena aliran rembesan tersebut dapat membawa butiran halus material penyusun dan jika berlangsung terus menerus menyebabkan erosi pondasi [8]. Erosi bawah tanah atau piping yang terjadi dibawah tubuh bendungan harus dilakukan pengecekan karena akan menyebabkan keruntuhan [9]. Perhitungan angka keamanan dari piping pada penelitian ini akan menggunakan perhitungan secara manual. Perhitungan angka keamanan dari piping yang terjadi dibawah tubuh bendungan akan dianalisis terhadap penerapan filter maupun tanpa penerapan filter.

Angka keamanan dari piping pada penelitian ini akan dihitung dengan menggunakan metode Harza sebagai berikut:

$S F=\frac{i_{c}}{i_{e}}$

\section{Dimana:}

$\mathrm{SF} \quad=$ safety factor (angka keamanan);

$I_{c} \quad$ = gradien keluaran kritis;

$I_{e} \quad=$ gradien keluaran dari hasil analisis rembesan atau pembacaan instrumen piezometer

Angka keamanan yang dianalisis untuk seluruh kondisi yaitu tanpa dan dengan filter akan dipilih yang memenuhi persyaratan atau ketentuan bendungan yaitu angka keamanan yang lebih besar dari 4 (SF > 4). Penerapan filter dibawah tubuh bendungan dianalisis dengan variasi 


\section{JURNAL FORUM MEKANIKA}

Vol. 10, No. 1, Mei 2021, P-ISSN: 2356-1491, E-ISSN: 2655-8211

DOI: https://doi.org/10.33322/forummekanika.v10i1.1266

kedalaman yaitu $40 \mathrm{~m}, 60 \mathrm{~m}$ dan $80 \mathrm{~m}$ pada kondisi muka air tinggi (HWL), muka air normal (NWL), surut cepat dan bendungan kosong atau tanpa air.

\section{HASIL DAN PEMBAHASAN}

\subsection{Angka Keamanan Tanpa Filter}

Angka keamanan bahaya piping tanpa penerapan filter seperti pada Gambar 2 untuk kondisi muka air tinggi atau maksimum (HWL) pada sta. 0+150 dihitung sebagai berikut:

$S F=\frac{i_{c}}{i_{e}}$

$I_{c}=\frac{G_{s}-1}{1+e}$

Dengan $G_{s}=2,62$

$$
e=0,30
$$

Maka,

$I_{c}=\frac{2,62-1}{1+0,30}=1,246$

$$
i_{e}=C \frac{h}{B}
$$

Dengan $B=50,16+4+10=64,16 m$

$d=E l 82-E l 77=5 \mathrm{~m}$

$h=E l 156,05-E l 78=78,05 m$

$B / d=64,16 / 5=12,8320$

$C=1,2462$ (menggunakan Grafik Gradien Keluar Kritis menurut Harza)

Maka $\quad i_{e}=1,2462 \frac{78,05}{64,16}=1,6909$

Sehingga, $S F=\frac{1,246}{1,6909}=\mathbf{0}, 7370<4$ (tidak aman)

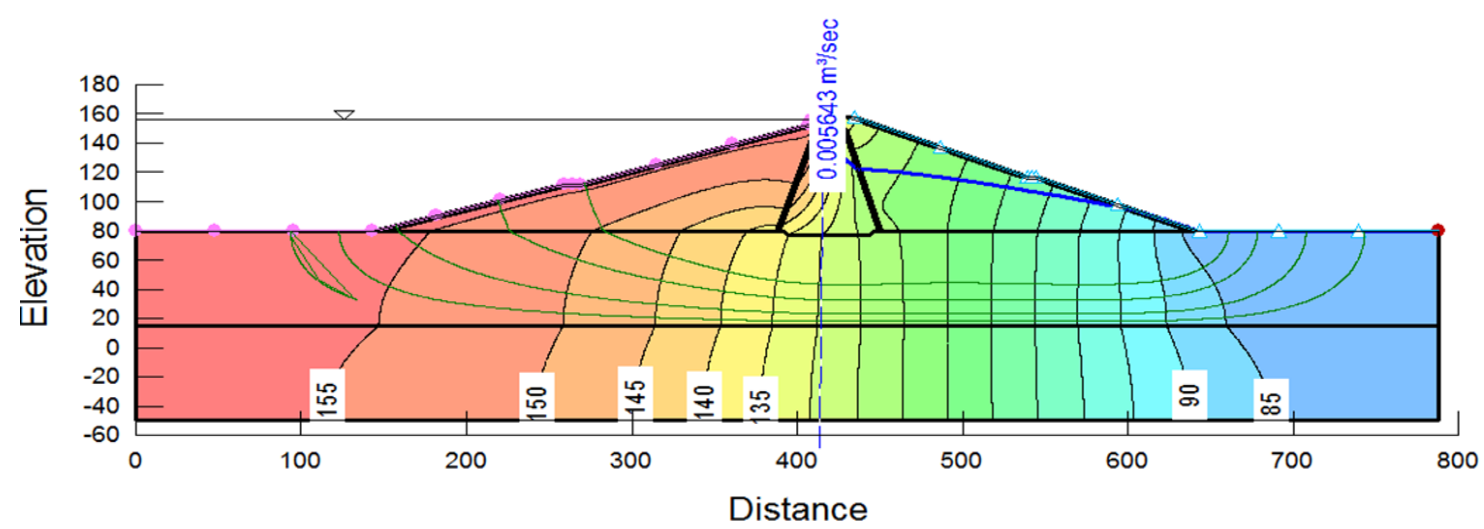

Gambar 2. Penampang Melintang Tubuh Bendungan tanpa Filter

Untuk perhitungan lainnya mengenai angka keamanan bahaya piping tanpa filter untuk sta $0+200$, sta $0+250$ dan sta $0+300$ dapat dilihat pada Tabel 3 berikut ini. 
JURNAL FORUM MEKANIKA

Vol. 10, No. 1, Mei 2021, P-ISSN: 2356-1491, E-ISSN: 2655-8211 DOI: https://doi.org/10.33322/forummekanika.v10i1.1266

Tabel 3. Angka Keamanan Piping Tanpa Penerapan Filter

\begin{tabular}{|c|c|c|c|c|}
\hline \multirow{2}{*}{ Kondisi } & \multicolumn{4}{|c|}{ Angka Keamanan } \\
\cline { 2 - 5 } & Sta. 0+150 & Sta. 0+200 & Sta. 0+250 & Sta. 0+300 \\
\hline HWL & 0,737 & 0,720 & 0,717 & 0,709 \\
\hline NWL & 0,799 & 1,000 & 0,777 & 0,769 \\
\hline Surut cepat & 1,046 & 1,022 & 1,018 & 1,006 \\
\hline Kosong & 8,217 & 8,029 & 7,996 & 7,907 \\
\hline
\end{tabular}

Sumber: analisis perhitungan

Berdasarkan Tabel 3 terlihat bahwa angka keamanan tertinggi dan memenuhi persyaratan angka keamanan bendungan atau $>4$ terdapat pada kondisi kosong, sedangkan pada kondisi muka air tinggi (HWL), muka air normal (NWL) dan surut cepat tidak memenuhi persyaratan minimum angka keamanan. Agar tubuh bendungan dalam keadaan aman, maka perlu penambahan filter atau grouting dibagian bawah tubuh bendungan. Untuk perhitungan atau analisis penerapan filter akan dibahas pada sub bab berikut.

\subsection{Angka Keamanan dengan Filter}

Besarnya angka keamanan dengan bahaya piping dengan penerapan filter dihitung dengan menggunakan persamaan yang sama dengan sebelumnya untuk semua kondisi mulai dari sta $0+150$, sta $0+200$, sta $0+250$ dan sta $0+300$. Hasil perhitungan angka keamanan dengan penerapan filter dapat dilihat pada Tabel 4 sampai dengan Tabel 6 berikut ini.

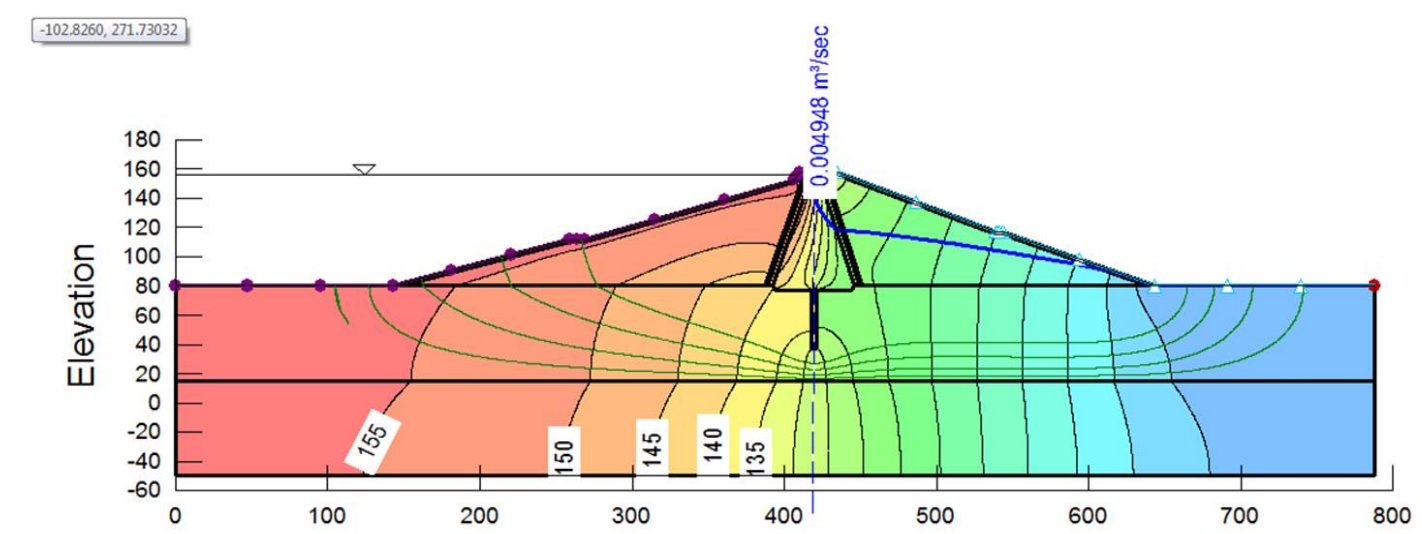

Gambar 3. Penerapan Filter dengan Grouting Sedalam $40 \mathrm{~cm}$ di Bawah Tubuh Bendungan

Tabel 4. Angka Keamanan Piping dengan Penerapan Filter $40 \mathrm{~cm}$

\begin{tabular}{|c|c|c|c|c|}
\hline \multirow{2}{*}{ Kondisi } & \multicolumn{4}{|c|}{ Angka Keamanan } \\
\cline { 2 - 5 } & Sta. 0+150 & Sta. 0+200 & Sta. 0+250 & Sta. 0+300 \\
\hline HWL & 2.696 & 2.656 & 2.784 & 2.615 \\
\hline NWL & 2.922 & 2.879 & 3.018 & 2.835 \\
\hline Surut cepat & 3.826 & 3.769 & 3.950 & 3.107 \\
\hline Kosong & 30.058 & 29.609 & 31.037 & 29.156 \\
\hline
\end{tabular}

Sumber: analisis perhitungan 


\section{JURNAL FORUM MEKANIKA}

Vol. 10, No. 1, Mei 2021, P-ISSN: 2356-1491, E-ISSN: 2655-8211

DOI: https://doi.org/10.33322/forummekanika.v10i1.1266

Berdasarkan hasil perhitungan pada Tabel 4 untuk penerapan filter dengan grouting dengan kedalaman $40 \mathrm{~cm}$ seperti yang terlihat pada Gambar 2, angka keamanan yang sudah memenuhi persyaratan piping terdapat pada kondisi kosong sedangkan pada kondisi yang lainnya angka keamanan yang didapatkan belum memenuhi atau < 4. Agar didapatkan angka keamanan, maka filter atau kedalaman grouting ditambahkan lagi menjadi $60 \mathrm{~cm}$. Perhitungan untuk kedalaman filter $60 \mathrm{~cm}$ akan dilihat sebagai berikut.

Tabel 5. Angka Keamanan Piping dengan Penerapan Filter $60 \mathrm{~cm}$

\begin{tabular}{|c|c|c|c|c|}
\hline \multirow{2}{*}{ Kondisi } & \multicolumn{4}{|c|}{ Angka Keamanan } \\
\cline { 2 - 5 } & Sta. 0+150 & Sta. 0+200 & Sta. 0+250 & Sta. 0+300 \\
\hline HWL & 3.659 & 3.794 & 4.231 & 4.184 \\
\hline NWL & 3.966 & 4.112 & 4.587 & 4.535 \\
\hline Surut cepat & 5.192 & 5.384 & 6.004 & 5.937 \\
\hline Kosong & 40.792 & 42.299 & 47.176 & 46.649 \\
\hline
\end{tabular}

Sumber: analisis perhitungan

Berdasarkan hasil perhitungan pada Tabel 5 untuk penerapan filter dengan grouting dengan kedalaman $60 \mathrm{~cm}$, angka keamanan yang sudah memenuhi persyaratan piping terdapat pada kondisi kosong, surut cepat diseluruh sta dan muka air normal khususnya di sta $0+200$, sta $0+250$ dan sta $0+300$, sedangkan pada kondisi muka air tinggi (HWL) angka keamanan yang didapatkan belum memenuhi atau < 4. Persyaratan angka keamanan harus memenuhi diseluruh sta, sehingga perlu penambahan filter atau grouting menjadi $80 \mathrm{~cm}$ yang dapat dilihat sebagai berikut.

Tabel 6. Angka Keamanan Piping dengan Penerapan Filter $80 \mathrm{~cm}$

\begin{tabular}{|c|c|c|c|c|}
\hline \multirow{2}{*}{ Kondisi } & \multicolumn{4}{|c|}{ Angka Keamanan } \\
\cline { 2 - 5 } & Sta. 0+150 & Sta. 0+200 & Sta. 0+250 & Sta. 0+300 \\
\hline HWL & 4.454 & 7.587 & 4.701 & 5.818 \\
\hline NWL & 4.828 & 8.225 & 5.096 & 6.299 \\
\hline Surut cepat & 6.320 & 10.767 & 6.671 & 8.246 \\
\hline Kosong & 49.660 & 84.599 & 52.418 & 64.790 \\
\hline
\end{tabular}

Sumber: analisis perhitungan

Berdasarkan hasil perhitungan pada Tabel 6 untuk penerapan filter dengan grouting dengan kedalaman $80 \mathrm{~cm}$, angka keamanan yang didaptkan sudah memenuhi persyaratan piping yaitu SF > 4 terdapat pada seluruh kondisi baik kondisi kosong, surut cepat, muka air normal (NWL) dan kondisi muka air tinggi (HWL). Sehingga filter atau grouting yang diterapkan dibawah tubuh bendung adalah dengan kedalaman $80 \mathrm{~cm}$, seperti yang terlihat pada Gambar 3 . 


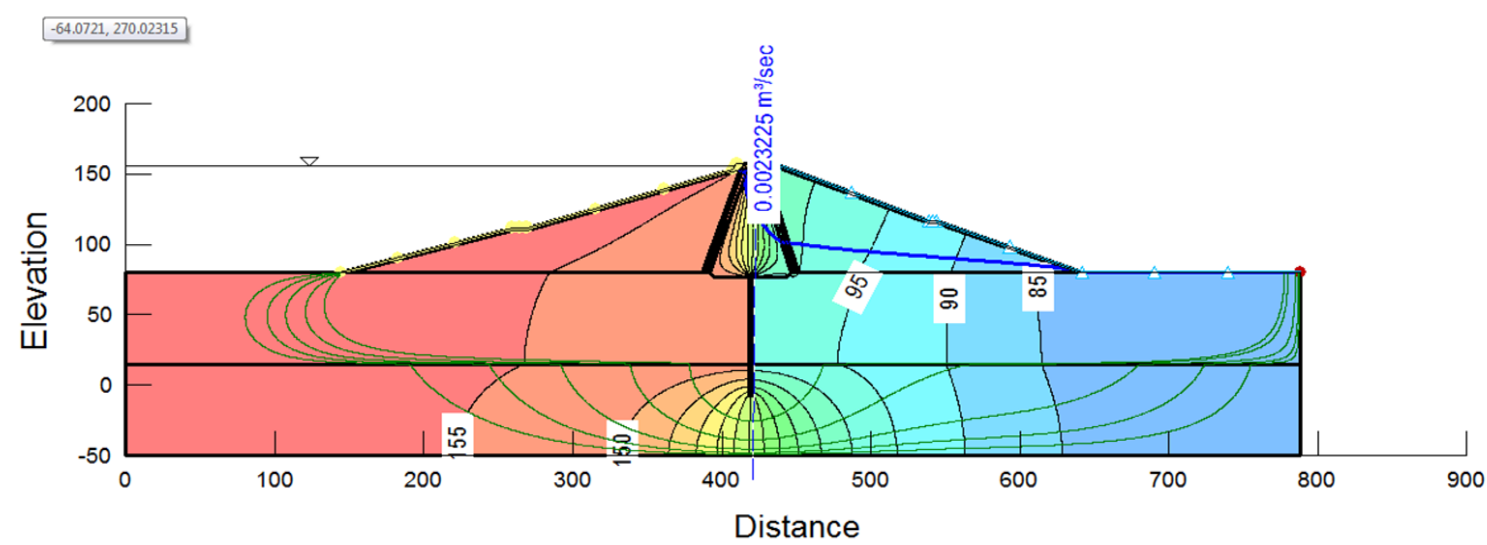

Gambar 3. Penerapan Filter dengan Grouting Sedalam $80 \mathrm{~cm}$ di Bawah Tubuh Bendungan

\section{KESIMPULAN DAN SARAN}

Berdasarkan hasil analisis atau perhitungan dengan metode Harza, penerapan filter dengan menggunakan grouting dibawah tubuh bendungan agar memenuhi persyaratan angka keamanan yang ditetapkan yaitu SF > 4 adalah sedalam $80 \mathrm{~cm}$ untuk seluruh sta yaitu sta $0+150$, sta $0+200$, sta 0+250 dan sta 0+300 pada semua kondisi di muka air tinggi (HWL), muka air normal (NWL), surut cepat dan bendungan kosong.

Sebagai penelitian selanjutnya maka dapat dilanjutkan perhitungan debit rembesan yang melalui tubuh bendungan maupun dibawah tubuh bendungan. Dapat pula dilakukan perhitungan angka keamanan bahaya piping dengan menggunakan metode lainnya seperti metode Lane dan metode Terzaghi sebagai bahan perbandingan.

\section{DAFTAR PUSTAKA}

[1] I. G. N. P. Dharmayasa, I. W. Redana, and T. G. Suwarsa Putra, "Analisis Keamanan Lereng Bendungan Utama Pada Bendungan Benel Di Kabupaten Jembrana," J. Spektran, vol. 2, no. 2, pp. 68-77, 2014, doi: 10.24843/spektran.2014.v02.i02.p09.

[2] B. A. Ikawanty, "Desain Kontrol Pintu Bendungan Otomatis Untuk Mencegah Banjir Menggunakan Vhdl,” J. ELTEK, vol. 11, no. 01, pp. 1693-4024, 2013, [Online]. Available: https://bulla-sipil.polinema.ac.id/index.php/eltek/article/view/8/8.

[3] B. Salehudin; Giri Putra, I B; Yatmi Widalia, "Analisis Sedimentasi Terhadap Umur Guna Bendungan Pengga Kabupaten Lombok Tengah," Spektrum Sipil, vol. 2, no. 1, pp. 71-81, 2015.

[4] G. W. R. Asmaranto, Runi; Wicaksono, Prima Hadi; Dewa, "Analisa Stabilitas Tubuh Bendungan (Studi Kasus Bendungan Lolak Sulawesi Utara)," 2007.

[5] T. N. F. Nanda and I. N. Hamdhan, "Analisis Rembesan dan Stabilitas Bendungan Bajulmati dengan Metode Elemen Hingga Model 2D dan 3D," Reka Racana, vol. 2 No.4 Des, no. 4, pp. 1-12, 2016.

[6] K. M. Murdiani, S. Sangkawati, and K. W. Sadono, "Pemodelan Keruntuhan Bendungan Menggunakan HEC-RAS 2D Studi Kasus Bendungan Gondang, Kabupaten Karanganyar," Rekayasa, vol. 13, no. 2, pp. 205-211, 2020, doi: 10.21107/rekayasa.v13i2.6872.

[7] I. Dharmayasa, "Analisis Rembesan Di Bawah Tubuh Bendungan Urugan," Padur. J. Tek. Sipil ..., vol. 7, pp. 53-62, 2018, [Online]. Available: https://www.ejournal.warmadewa.ac.id/index.php/paduraksa/article/view/817. 


\section{JURNAL FORUM MEKANIKA}

Vol. 10, No. 1, Mei 2021, P-ISSN: 2356-1491, E-ISSN: 2655-8211

DOI: https://doi.org/10.33322/forummekanika.v10i1.1266

[8] H. Setyawati, N. Najib, and A. S. Hidayatillah, "Analisis Rembesan pada Perencanaan Pembangunan Bendungan Logung," J. Geosains dan Teknol., vol. 1, no. 3, pp. 99-106, 2016.

[9] D. A. Arif, S. R. Giyarsih, and D. Mardiatna, "Kerentanan Masyarakat Perkotaan terhadap Bahaya Banjir di Kelurahan Legok, Kecamatan Telanipura, Kota Jambi," Maj. Geogr. Indones., vol. 31, no. 2, p. 79, 2017, doi: 10.22146/mgi.29779. 